\title{
Research needs and prioritizations for studies linking dietary sugars and potentially related health outcomes
}

\author{
Mei Chung ${ }^{1 *}$ D, Ding Ding Wang ${ }^{1,2}$, Edward Archer $^{3}$, Janine Higgins ${ }^{4}$, Sery Kim ${ }^{5}$, Maren Laughlin ${ }^{6}$, Lu Qi ${ }^{7}$, \\ Susan Raatz ${ }^{8}$, Richard D. Siegel ${ }^{9}$, Joanne Slavin ${ }^{10}$, Dan Steffen ${ }^{11}$, Hope Warshaw ${ }^{12}$ and Alice M. Tang ${ }^{1}$
}

\begin{abstract}
Background: Relationships among dietary sugars and a variety of chronic diseases have spawned interest in investigating the metabolic effects of dietary sugars. An approach developed by the Agency for Healthcare Research and Quality (AHRQ) for assessing Future Research Needs (FRN) was implemented with modifications that integrated an evidence mapping process.
\end{abstract}

Methods: A panel of 14 stakeholders across 7 pre-defined areas of expertise (lay audience, policy makers, health providers, research funders, evidence-based methodologists, product makers, and researchers) was assembled to prioritize research needs. The panel was facilitated by an independent research team. A total of 213 studies were analyzed descriptively for evidence mapping, and the results were used to inform the stakeholder panel discussions on research needs.

Results: The stakeholder panel identified and prioritized 14 sets of research questions. The top three high-priority FRN questions selected by the stakeholder panel focused on the effects of dietary sugars on body weight or body composition, fat deposition, and satiety and appetite. Research considerations for the top three research questions and crosscutting research design issues are discussed.

Conclusion: Involving a multidisciplinary stakeholder panel to prioritize the direction of future research in this or other content areas has potential to add diverse perspectives to the determination of research needs, and to the development of public health policy.

Keywords: Future research needs projects, Sugars, Body weight, Body composition, Appetite, Satiety

\section{Background}

Systematic reviews are valuable not only to synthesize evidence to inform policy or practice, but also to identify the 'evidence gaps' or 'research gaps' that limit their ability to answer the questions posed. Structured approaches for examining the results of systematic reviews and prioritizing research gaps from systematic reviews have recently become more common and developed [1]. The main advantages of these approaches include the transparency of the process, results that are easily

\footnotetext{
* Correspondence: Mei_Chun.Chung@tufts.edu

${ }^{1}$ Nutrition/Infection Unit, Department of Public Health and Community Medicine, School of Medicine, Tufts University, Medford, USA

Full list of author information is available at the end of the article
}

interpretable, and the need for modest resources in terms of funds and time required. As part of a new effort in 2010, the Agency for Healthcare Research and Quality (AHRQ) supported a series of Future Research Needs (FRN) projects, in which stakeholders were engaged after the completion of comparative effectiveness reviews to help develop and prioritize the future research needed by decision makers in a variety of healthcare content areas [2]. Concurrently a series of research papers on various methodologic issues identified through the initial pilot FRN projects was published to inform eventual guidance on the determination and prioritization of future research needs for the AHRQ's Effective Health Care (EHC) Program [3]. In the AHRQ EHC program, the FRN process begins by identifying a 
list of evidence gaps from a systematic review. Then the systematic review team works with a stakeholder panel to first elaborate and then consolidate the evidence gaps. Potential research questions are then formalized following the PICOTS (Population, Intervention, Comparator, Outcome, Timing, and Study Design) framework with the exception of methodological questions. Finally, the research questions are prioritized by the stakeholders according to a set of criteria on potential value of the research [1].

The purpose of this paper is to present the methods and results of an FRN project which utilized a modified version of the AHRQ's FRN framework for identifying research priorities [1]. Specifically, in addition to the research gaps identified from published systematic reviews (which is the current AHRQ FRN process), we integrated an evidence mapping of primary research studies with input from a multidisciplinary stakeholder panel. The panel members identified and prioritized research needs linking dietary sugars and potentially related health outcomes, based on their broad range of expertise. To our knowledge, the present project is the first FRN project with a goal to cover research questions beyond those that were identified by systematic reviews because of the need for covering research questions that are important for public health nutrition.

Dietary sugars commonly refer to monosaccharides and disaccharides. Monosaccharides include glucose, galactose, and fructose. Fructose is the most common naturally occurring monosaccharide, found in fruits and vegetables. Common disaccharides include sucrose (glucose plus fructose), lactose (glucose plus galactose), and maltose (glucose plus glucose). Associations among dietary sugars and a variety of chronic diseases such as obesity have spawned interest in investigating the metabolic effects of sugars in general. Several systematic reviews have been published focusing on the effects of fructose on cardiometabolic outcomes in controlled trials [4-9]. Other systematic reviews have examined the effects of dietary sugars on body weight [10, 11], and non-alcoholic fatty liver disease or indices of liver health [12], including both controlled trials and observational studies. Due to the complex relationships between dietary sugars and health outcomes there is a need to review a large array of populations, outcomes of interest, and types of studies to identify and prioritize the research gaps in this research area. This paper will summarize the FRN approach we used and the stakeholder panel's perspectives on the top three research needs identified by this approach.

\section{Methods}

The initial scope of work was developed by the sponsor of this project (International Life Sciences Institute (ILSI)) in a request for proposals. Aside from their initial feedback on our funded research proposal, the sponsor was not involved in the later refinement of the scope of work or the process of creating the evidence-mapping database, other than providing a list of selected citations for cross-referencing purposes. The list of selected citations suggested by the sponsor was merged with the citations identified by our literature search, and were evaluated in the same way based on the study eligibility criteria (Table 1).

\section{Overall approach of this FRN project}

An overview of the FRN approach we used is shown in Fig. 1. The project consisted of a research team and a

Table 1 Study eligibility criteria

\begin{tabular}{|c|c|c|}
\hline & Inclusion Criteria & Exclusion Criteria \\
\hline \multirow[t]{5}{*}{ Step 1 evidence map } & \multirow{2}{*}{$\begin{array}{l}\text { Sugar Exposures: Sucrose, fructose, sugar-sweetened } \\
\text { beverages, high fructose corn syrup, and total, refined } \\
\text { and other unspecified sugars. }\end{array}$} & $\begin{array}{l}\text { Study Designs: Case-control and cross-sectional studies, } \\
\text { and in vitro studies. }\end{array}$ \\
\hline & & \multirow[t]{2}{*}{ Language: Non-English publications. } \\
\hline & $\begin{array}{l}\text { Study Designs: Intervention studies of any design }{ }^{\text {a }} \text { \& } \\
\text { cohort studies. } \\
\text { Outcomes: Any clinical diagnosis, patient-centered outcome, } \\
\text { and well-established intermediate endpoints indicative of } \\
\text { disease risk }\end{array}$ & \\
\hline & \multirow[t]{2}{*}{ Populations: Human } & Outcomes: Dental caries and pain. \\
\hline & & Populations: Animals \\
\hline \multirow[t]{4}{*}{ Step 2 evidence map } & Sugar Exposures and Study Designs: Same as Step 1. & \multirow{2}{*}{$\begin{array}{l}\text { Sugar Exposures and Study Designs: Intravenous sugar } \\
\text { administration and sugar-sweetened beverages without } \\
\text { quantification of sugar amount. }\end{array}$} \\
\hline & \multirow[t]{3}{*}{ Additional Outcomes to Step 1: Satiety, "addiction,"'b and appetite } & \\
\hline & & Outcomes: Cancer, athletic performance, and cognition. \\
\hline & & Populations: Infants (age < 1 year old) \\
\hline
\end{tabular}

${ }^{a}$ Note that study design filters for randomized trials and prospective cohort studies were utilized in our search strategy. Therefore, non-randomized trials and before-and-after trials were not completely captured by our literature search. 'The outcome term "addiction" was later removed based on the stakeholder panel's discussions to avoid misinterpretations. See results for stakeholders' discussions on this issue 


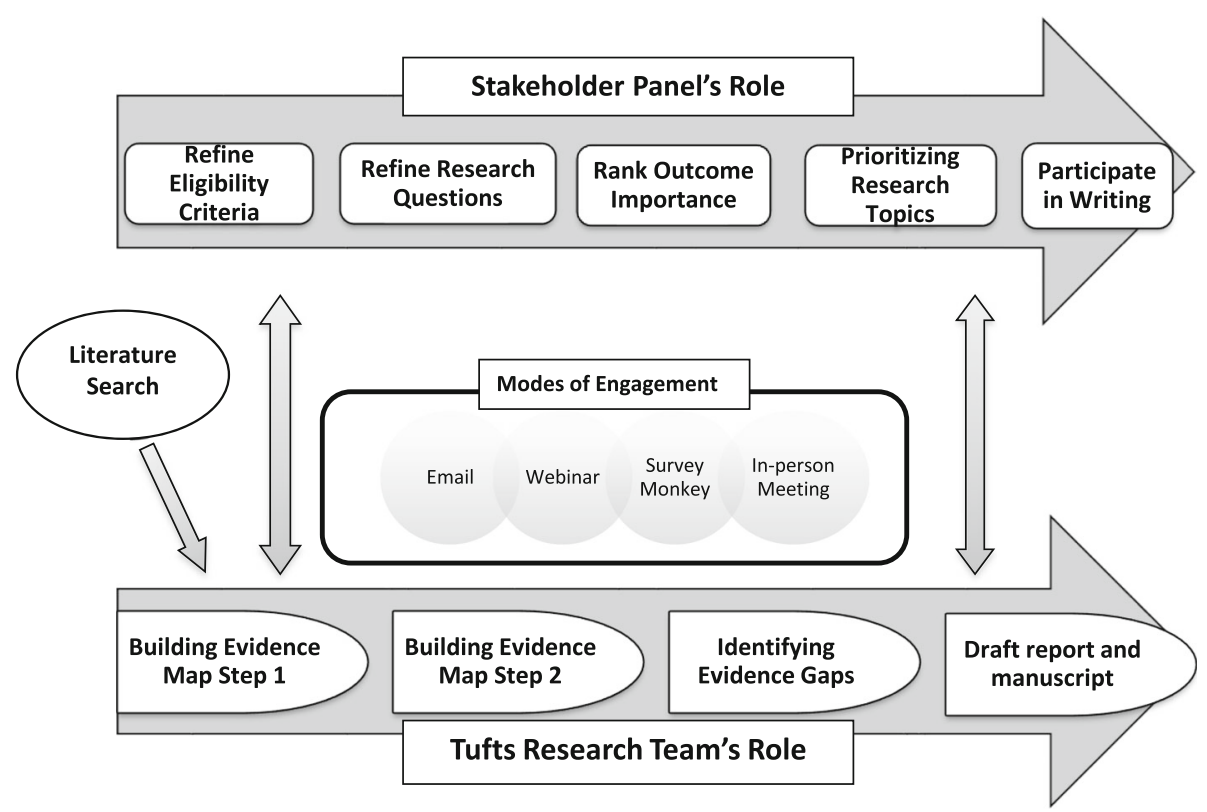

Fig. 1 Overview of the FRN assessment approach

stakeholder panel. The stakeholder panel was tasked with overseeing and advising on the development of the search strategy and study eligibility criteria for the evidence mapping, as well as prioritization of FRN research questions. The research team was tasked with data screening, abstraction and analysis, and facilitating stakeholder engagement and discussions. The roles and responsibilities of different parties in the FRN project are described in Appendix A of the Additional file 1.

A draft report underwent a period of public review in August 2014. All public reviewers' comments and suggestions were considered in revising the report.

\section{Evidence mapping}

The process and methods for creating an evidence-map database of published studies linking dietary sugars and selected health outcomes are described in the Additional file 2 . There are currently no methodological standards for evidence mapping. The steps of our evidence mapping included: 1) developing a comprehensive literature search strategy; 2) establishing study eligibility criteria and a systematic study selection process; 3) extracting data; 4) developing groups of health outcomes with input from the stakeholder panel; and 5) tabulating data using descriptive analyses [13]. One of the most important features of the evidence mapping process is the cataloging of a large number and variety of outcomes reported in the published literature. For this project, the research team solicited feedback from the stakeholder panel to ensure that the results would be useful for their discussion on research needs. Outcomes were grouped into clinically and biologically relevant categories based on stakeholder input and the research team's expertise. (Fig. 2) A summary report of the descriptive evidencemapping analysis was then presented to the stakeholder panel to generate discussion about research gaps and future research needs, which took place during a oneday in-person meeting (see Appendix $B$ of the Additional file 1). All data were stored on SRDR ${ }^{\mathrm{ms}}$ (available on http://srdr.ahrq.gov/projects/136). The goal of the stakeholder panel's discussions was to bring out different perspectives on the research questions and priorities. Therefore, scientific evidence was not required to support the statements or opinions raised by the stakeholder panel.

\section{Stakeholder panel}

Stakeholders with various areas of expertise were identified and assembled according to a framework for stakeholder engagement in patient-centered outcomes research [14]. Stakeholders were selected to provide broad expertise and perspectives specific to the topic of dietary sugars and health. A total of 14 stakeholders with different backgrounds and expertise were initially identified through existing networks of both the sponsor and the research team (Table 2). Two members (1 lay audience and 1 statistical expert) dropped out due to personal reasons. The final stakeholder panel consisted of 12 members across seven stakeholder groups. Ten members participated as coauthors of the full report and this publication. 


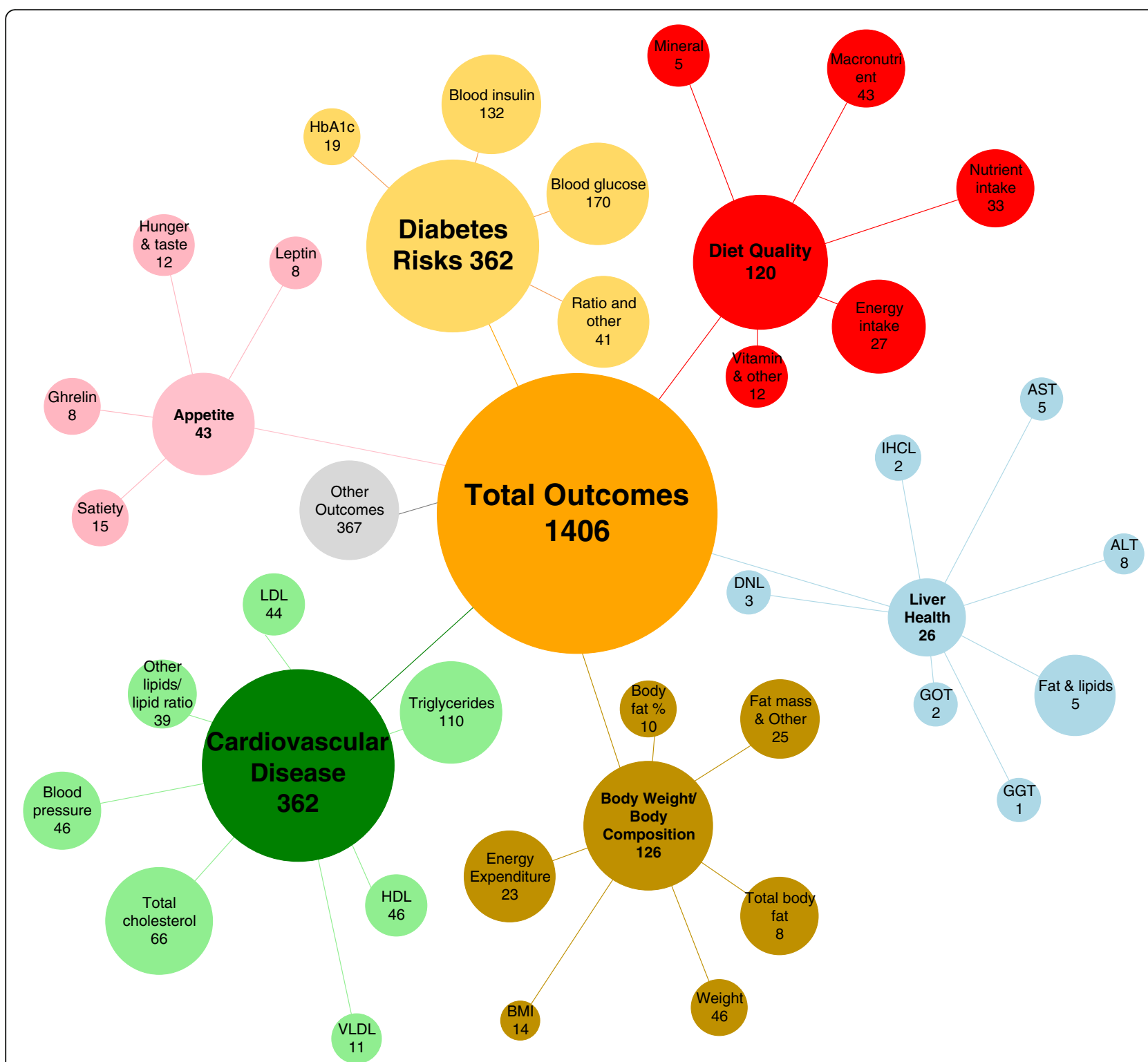

Fig. 2 Analysis of outcomes reported in the studies in step-2 evidence map database by the outcome groups ${ }^{a}$ ranked as highest priority by the stakeholder panel ${ }^{b}$. Legends: ' Seven outcome groups were formed, namely 'cardiovascular disease risks,' 'diabetes risks, 'body weight/body composition,' 'appetite,' 'liver health,' 'diet quality,' and 'mortality.' Note top 7 categories include mortality but no studies reporting mortality outcome were identified in our evidence-mapping database. Total outcomes included 367 outcomes in the "other" category. ${ }^{b}$ Outcome groups are displayed in different colors Cardiovascular Disease Risks (green bubbles), Diabetes Risks (light orange bubbles), Body weight/ Body Composition (combined groups, yellow bubbles), Diet Quality (red bubbles), Appetite (pink bubbles), and Liver Health (light blue bubbles). Numeric number in each bubble shows the number of studies in each outcome category. Abbreviations: Liver health: ALT- alanine aminotransferase, AST- aspartate aminotransferase, GGT- Gamma-glutamyl transpeptidase, GOT- serum glutamic-oxaloacetic Transaminase, DNL- de novo lipogenesis, IHCL-intrahepatic content of lipid, Cardiovascular disease risk: LDL- low density lipoprotein cholesterol, HDL- high-density lipoprotein cholesterol, VLDL-very low-density lipoprotein

\section{Stakeholders engagement and research needs prioritization}

Stakeholders participated in a one-day in-person meeting, chaired by the principal investigator (M.C.), to discuss, refine, and formulate research questions based on the top eight outcome groups. Prior to the in-person meeting, 25 preliminary research questions were drafted based on the research recommendations made by the authors of the published systematic reviews and the research gaps identified by the evidence-mapping analyses. Stakeholders provided input through comments and discussions posted on a web-based discussion forum. During the in-person meeting, the stakeholder panel discussed and revised these preliminary research questions. After the in-person meeting, the stakeholder panel provided additional input through emails and a webinar to 
Table 2 Initial FRN Stakeholder Panel

\begin{tabular}{|c|c|c|}
\hline $\begin{array}{l}\text { Stakeholder } \\
\text { Group }\end{array}$ & $\begin{array}{l}\text { Number of } \\
\text { stakeholders } \\
\text { in group }\end{array}$ & $\begin{array}{l}\text { Conflict of Interest } \\
\text { Disclosures }\end{array}$ \\
\hline Lay audience & $2^{\mathrm{a}}$ & None disclosed \\
\hline Policy maker & 1 & None disclosed \\
\hline Health Provider & 2 & None disclosed \\
\hline Research funder & 1 & $\begin{array}{l}\text { Have grants relating } \\
\text { to fructose and sugar } \\
\text { metabolisms }\end{array}$ \\
\hline $\begin{array}{l}\text { Evidence-base } \\
\text { methodologist }\end{array}$ & 1 & None disclosed \\
\hline $\begin{array}{l}\text { Product maker } \\
\text { (nonvoter) }\end{array}$ & 1 & None disclosed \\
\hline $\begin{array}{l}\text { Researcher } \\
\text { (intervention) }\end{array}$ & 2 & $\begin{array}{l}\text { Have grants relating } \\
\text { to glycemic effects } \\
\text { of honey, sugars and } \\
\text { high fructose corn } \\
\text { syrups }\end{array}$ \\
\hline $\begin{array}{l}\text { Researcher } \\
\text { (epidemiology) }\end{array}$ & 2 & $\begin{array}{l}\text { Students and post-doc } \\
\text { received unrestricted } \\
\text { funds from Coca-Cola }\end{array}$ \\
\hline Statistics & $1^{\mathrm{a}}$ & None disclosed \\
\hline
\end{tabular}

${ }^{\mathrm{a}}$ The final stakeholder panel included 12 individuals. One lay audience and one statistician dropped out due to personal reasons

refine and combine the research questions before the final topic prioritization. A total of 14 sets of research questions were agreed to by the stakeholder panel. The Effective Health Care (EHC) Program Selection Criteria [15] (with slight modifications for applications to the field of public health nutrition) was then used to prioritize the research questions. Each stakeholder was asked to prioritize the research questions considering four dimensions (importance, desirability, feasibility, and potential impact), giving a score ranging from 1 (not very important) to 5 (very important) for each dimension. An overall priority score was then calculated by averaging the four dimension scores from all stakeholders for each FRN research question.

\section{Results}

The literature search identified over 13,000 citations. Of these, a total of 708 potentially relevant full-text articles were screened, and 213 studies (202 intervention studies and 11 prospective cohort studies) were included in our final evidence-mapping database. (Fig. 3) Table 3 summarizes the study design and population characteristics of the intervention studies in the evidence map. Briefly, the study populations were mostly adults (90\%), 52\% were healthy at study entry, and $62.6 \%$ were males. Study sample sizes ranged from 5 to 2,026 (mean 45) with mean age of 35.4 and mean BMI of $23.8 \mathrm{~kg} / \mathrm{m}^{2}$. Over a third (36\%) of these trials were studies with a duration of $<1$ day. All 11 cohort studies [16-26] were conducted in adults, of which eight were in healthy populations, one in pregnant women, one in diabetics, and one in a study population with mixed health status. The sample sizes of these cohorts were large (mean sample size $=35,738$ ) with a wide range of follow-up time (4 to 48 years).

The complete FRN prioritization results are described in Table 4. Specific findings related to the top three research questions are summarized below and in Table 5 .

\section{High priority research question 1}

What is the long-term ( $>1$ year) effect of a reduction in the intake of sugars on body weight or body composition in overweight or obese adults and children?

\section{Evidence mapping}

A total of 53 intervention studies in our evidence map reported on body weight or body composition outcomes. Of these, 13 studies were conducted in overweight or obese populations. There were an equal number of studies examining the effects of isolated fructose or sucrose on body weight, but fewer studies examining the effects of sucrose or other sugars on body composition outcomes compared to studies of isolated fructose. Only two studies had intervention durations of longer than three months. None lasted for more than one year. Of the 11 cohort studies [16-26], one study in adults investigated the relationship between simple or added sugars and change in waist circumference after five years [20].

A published systematic review and meta-analysis of randomized controlled trials and prospective cohort studies concluded that among free living people on ad libitum diets, intake of dietary sugars or sugar sweetened beverages is a determinant of body weight [10]. The findings suggested that the change in body composition that occurs with modifying intakes is mediated by changes in energy intake, since iso-energetic exchange of sugars with other carbohydrates was not associated with weight change. Note that this systematic review and metaanalysis was used to support the 2014 draft WHO guidelines on intake of sugars for adults and children [27].

\section{Stakeholder discussions}

There are several challenges in conducting research on this topic that need greater emphasis. The stakeholder panel agreed that in addition to body weight, body composition should also be measured in future studies. Currently, there are several tools available for measuring body composition, such as Dual energy X-ray absorptiometry (DEXA). DEXA is used as the gold standard (over 99\% accuracy) for measuring whole body adiposity but requires specialized equipment and is therefore expensive and cannot be measured in large, field trials. Waist to hip ratio is commonly used to measure body composition. 


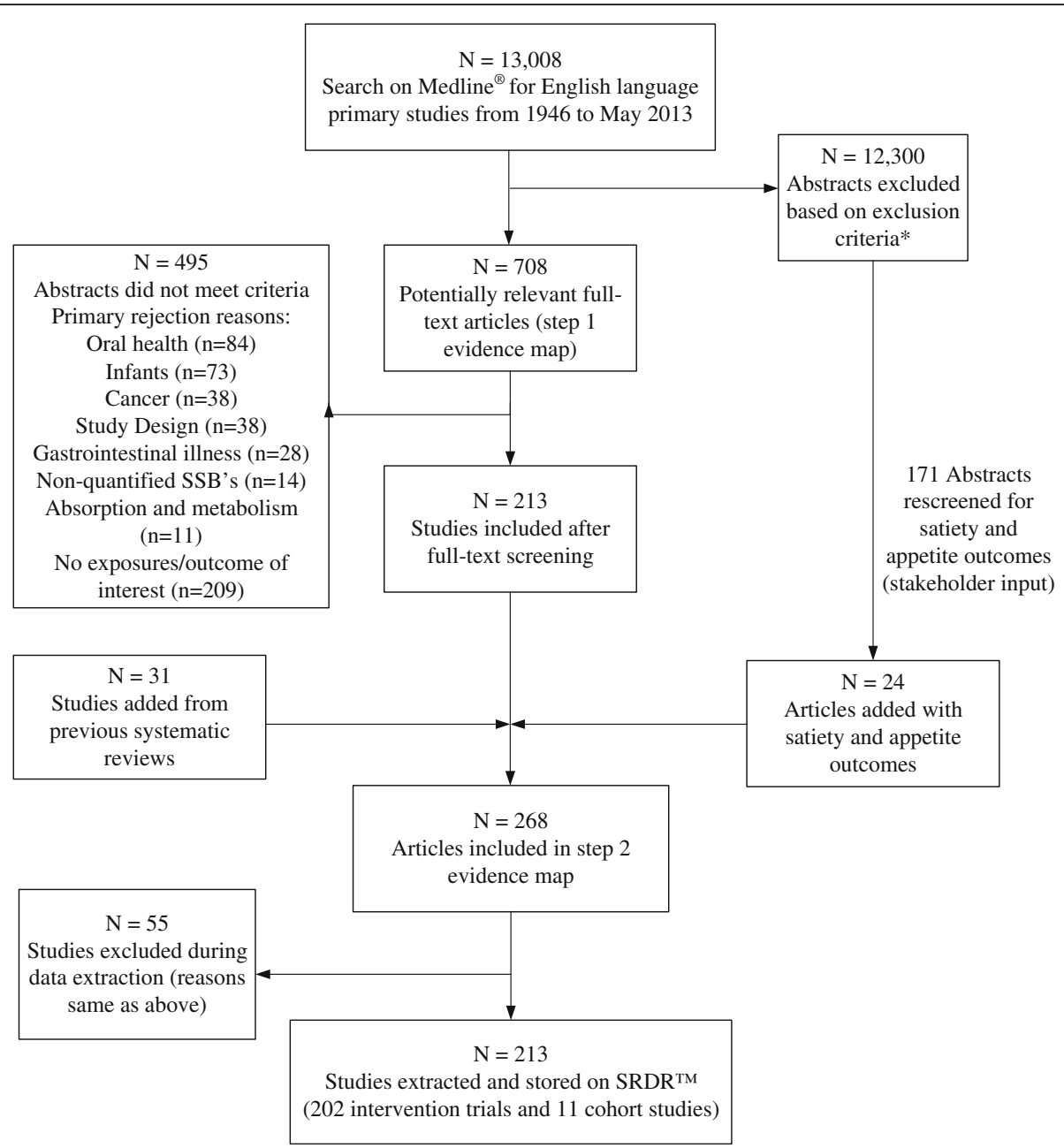

Fig. 3 Literature Search and Selection Process for Evidence Mapping. Legends: *Exclusion reasons were not tracked at this stage. A low threshold was used to exclude irrelevant abstracts, such as animal or in vitro studies, studies with no sugar exposures or outcomes of interest

The stakeholder panel discussed the possibility that healthy people maintain body weight through physical activity. Thus it is important to objectively measure physical activity when designing studies to address this research question (also see Table 6 for cross-cutting study design considerations). Furthermore, there is a need to examine whether there are differences in the long-term ( $>1$ year) effects of dietary sugars on body weight or body composition between healthy and overweight or obese populations. The stakeholder panel considered the possibility that overweight or obese adults and children might be more susceptible to the effects of "high" sugars intake (not well defined) on body weight compared to healthy counterparts, but there are no studies addressing this question.

\section{High priority research question 2}

Do dietary sugars have a different impact on the location of body fat deposition than other macronutrients?

\section{Evidence mapping}

Body fat deposition is related to body composition but specifically refers to the patterns or locations of body fat distribution. There were no studies investigating the effects of dietary sugars on locations of body fat deposition in the evidence-mapping database, and no published systematic reviews on this topic as of May 2013.

\section{Stakeholder discussions}

The question regarding the effects of dietary sugars versus other nutrients on fat deposition was first brought up by the lay audience stakeholder in lay terms ("whether consuming sugars would put more fat on my waist than on other parts of my body?"). This question was then translated into a research question by the expert stakeholders in the panel. The panel agreed that basic science in this area is limited, especially on how sugars may selectively drive fat deposition and whether 
Table 3 Summary of study design and population characteristics of the included intervention studies $(N=202)$

\begin{tabular}{|c|c|}
\hline & $n(\%)$ or mean (min - max) \\
\hline \multicolumn{2}{|l|}{ Design } \\
\hline Randomized (Parallel) & $47(23 \%)$ \\
\hline Randomized (Crossover) & $95(47 \%)$ \\
\hline Non-randomized & $25(12 \%)$ \\
\hline Single-arm & $25(12 \%)$ \\
\hline Undefined trial & $10(5 \%)$ \\
\hline \multicolumn{2}{|l|}{ Study Length } \\
\hline Acute (<1 day) & $72(36 \%)$ \\
\hline Non-acute ( $\geq 1$ day) & $123(61 \%)$ \\
\hline \multicolumn{2}{|l|}{ Study Duration, day } \\
\hline $1-14$ & $54(44 \%)$ \\
\hline $15-30$ & $21(17 \%)$ \\
\hline $30-60$ & $20(16 \%)$ \\
\hline $60-90$ & $8(7 \%)$ \\
\hline $90-120$ & $10(8 \%)$ \\
\hline$>120$ & $10(8 \%)$ \\
\hline Sample Size & $45(5-2026)$ \\
\hline Age, $y^{a}$ & $35.4(5-72)$ \\
\hline$\%$ Male $^{a}$ & $62.6 \%$ \\
\hline $\mathrm{BMI}, \mathrm{kg} / \mathrm{m}^{2 \mathrm{a}}$ & $25.8(18-35)$ \\
\hline \multicolumn{2}{|l|}{ Study Population } \\
\hline Adults & $181(90 \%)$ \\
\hline Children & $11(5 \%)$ \\
\hline Adolescents & $3(1.5 \%)$ \\
\hline Mixed & $7(3.5 \%)$ \\
\hline \multicolumn{2}{|l|}{ Baseline Health Status } \\
\hline Healthy & $104(52 \%)$ \\
\hline Overweight/Obese & $24(12 \%)$ \\
\hline Diabetes & $51(25 \%)$ \\
\hline Other & $23(11 \%)$ \\
\hline
\end{tabular}

Data missing for age: $n=13, \%$ male: $n=17$, and BMl: $n=114$. The unit of analysis is one study

sugars are different in terms of their effects on fat deposition compared to other energy containing nutrients such as protein or fat. The stakeholder panel discussed the fact that fructose, and possibly sugars in general, would likely drive fat deposition under hyper-caloric conditions based on the findings from studies of hypercaloric fructose feeding on de novo lipogenesis. Age, gender, ethnicity, physical activity and exercise are also likely to play a role in individual metabolism. A related research gap is whether disease risks change with the location of fat deposition (subcutaneous versus visceral) in response to sugars intake.
High priority research question 3

What is the effect of sugars intake on satiety and hunger mechanisms?

Does sugars intake affect leptin and ghrelin levels, appetite, or fullness?

What are the different effects on satiety and appetite between different types of sugars (fructose, sucrose, high fructose corn syrup, honey, added sugar vs. intrinsic)?

\section{Evidence mapping}

Currently, the appetite control literature includes mainly short-term experimental studies. In the evidence map, a total of 32 intervention studies reported outcomes related to appetite, such as satiety, ghrelin, leptin, hunger, appetite score, caloric compensation, peptide tyrosine tyrosine (PYY), saliva flow, and taste. Of these, 31 studies were conducted in young adults (mean age of 30 years) with an average BMI of $26.0 \mathrm{~kg} / \mathrm{m}^{2}$ (average of mean BMI across studies) and trial durations ranging from 1 day to 16 weeks. There were no published systematic reviews on this topic as of May 2013.

\section{Stakeholder discussions}

It appears that little is known about the relationships among sugars, appetite, and brain responses in humans, although this has been examined in animal models $[28,29]$. One stakeholder pointed out that the current evidence shows that appetite is mainly driven by brain mechanisms. Other stakeholders mentioned that obesity and body composition are also related to appetite. The literature from animal studies suggest that sugars may attenuate the brain's satiety responses and thus alter appetite. However there is little data supporting this in humans and more research is needed in this area.

The focus of this research question was whether people compensate for calories from sugars by eating less of other foods or if sugars had a particular characteristic that facilitated individuals to overcome the usual compensatory mechanisms, thus resulting in people who consume sugars eating more calories than they would otherwise. Some researchers relate these mechanisms to the overstimulation of reward systems similar to drug addiction, and feel strongly that the form (liquid versus solid) in which sugars are presented may be important for this question. However, this hypothesis has not been verified by the level of hunger or by the level of biological mechanism, e.g. satiety hormones or other satiety signal levels. There is currently only one experimental study (crossover design) in humans that compared the effect of liquid versus solid forms of sugars on weight or adiposity and appetite in seven males and eight females [30]. No significant differences in hunger (self-reported measures using a hunger questionnaire) between liquid and solid load periods were found in this study. A larger study is needed to address this question. 
Table 4 Research Question Prioritization Results

\begin{tabular}{|c|c|c|}
\hline $\begin{array}{l}\text { Average } \\
\text { score }\end{array}$ & Outcome Group & Research Questions \\
\hline 4.20 & Body weight or body composition & $\begin{array}{l}\text { What is the long-term ( }>1 \text { year) effect of a reduction in the intake of sugars on body weight or } \\
\text { body composition in overweight/obese adults and children? }\end{array}$ \\
\hline 4.03 & Body weight or body composition & $\begin{array}{l}\text { Do dietary sugars have a different impact on the location of body fat deposition than other } \\
\text { macronutrients? }\end{array}$ \\
\hline 3.95 & Satiety or Appetite & $\begin{array}{l}\text { a. What is the effect of sugars intake on satiety and hunger mechanisms? b. Does sugars intake } \\
\text { affect leptin and ghrelin levels, appetite, or fullness? c. What are the different effects on satiety } \\
\text { and appetite between different types of sugars (fructose, sucrose, high fructose corn syrup, honey, } \\
\text { added sugar vs. intrinsic)? }\end{array}$ \\
\hline 3.83 & Diet quality and body weight & $\begin{array}{l}\text { Does food source (i.e., food vs. beverage) modify the effect of sugars intake on total caloric intake, } \\
\text { body weight, and body composition? }\end{array}$ \\
\hline 3.69 & Satiety or Appetite & $\begin{array}{l}\text { a. What are the mechanistic pathways in the brain linking sugar consumptions to a reward system } \\
\text { ("addictive behavior") or insulin and glycemic levels? b. Does taste play a role in the process? }\end{array}$ \\
\hline 3.68 & Diabetes risk & $\begin{array}{l}\text { How do differing patterns of dietary sugar consumption affect glycemia in pre-diabetic children, } \\
\text { adolescents and adults, and can dietary sugar contribute to the onset of type } 2 \text { diabetes? }\end{array}$ \\
\hline 3.68 & Liver fat or liver health & $\begin{array}{l}\text { a. What are some factors that may modify the effects of dietary sugars on liver fat? b. Does sugar } \\
\text { consumption contribute to fatty liver independent of other factors? c. Does sugars intake modify } \\
\text { liver fat in the absence of a hyper-caloric diet? }\end{array}$ \\
\hline 3.67 & Cardiovascular disease risks & What factors modify the effects of sugars intake on cardiovascular disease outcomes? \\
\hline 3.65 & Diabetes risk & What factors modify the effects of sugars intake on the complications of diabetes? \\
\hline 3.55 & Cardiovascular disease risks & $\begin{array}{l}\text { Does type, form, source, or timing of dietary sugars have different effects on cardiovascular disease } \\
\text { outcomes? }\end{array}$ \\
\hline 3.55 & Diet quality & How does a diet high in added sugars affect the overall diet quality as compared to a low sugars diet? \\
\hline 3.30 & Diabetes risk & What are the effects of sugars intake on the complications of diabetes (type 1 or type 2 diabetes)? \\
\hline 3.15 & Cardiovascular disease risks & What are the effects of sugars intake on intermediate markers of atherosclerosis? \\
\hline 2.98 & Satiety or Appetite & Is physical activity associated with a reduced sugars intake in adults? \\
\hline
\end{tabular}

There are many methodological issues in the assessment of satiety. Objective tools for consistently measuring satiety, hunger or appetite outcomes are greatly needed. Factors such as culture, level of anxiety, and physical activity can impact eating behavior but are technically difficult to incorporate in studies with currently available measures of appetite or satiety such as leptin, ghrelin, or adipokine levels. The need for objective tools that can be obtained on larger study samples for consistently measuring satiety, hunger or appetite outcomes is enormous.

The stakeholder panel agreed that this research topic has sufficient evidence from animal studies, but not from human studies. Although it is feasible to address this research question in humans, this topic was suggested to be of lower priority unless objective measurement tools that can be used in large population-based studies for measuring satiety, hunger or appetite outcomes are developed.

The stakeholder panel also discussed considerations for future studies related to the top three high priority research questions (Table 5), and identified crosscutting study design considerations for future research (Table 6).

\section{Discussion}

This FRN report is intended to be used by researchers and funders to help improve the usefulness of the body of research evidence for decision makers [2]. This FRN assessment ranked research questions regarding dietary sugars that are of interest to general consumers, health care professionals, and scientific researchers. Research questions on body weight and appetite were ranked higher than questions relating to disease risks in this project. To our knowledge, this is the first FRN project to integrate evidence mapping to support an FRN assessment. Evidence mapping appears to be a useful process to inform the stakeholder panel on the scope, breadth, characteristics, and quantity of research on a broad topic. A birds eye view of a broad research landscape can provide information on trends in known research topics and emerging new areas of research. The evidence mapping also highlights where the research gaps exist, and may empower stakeholders who are not familiar with the topic areas to participate in the FRN discussions. Because this structured FRN approach is systematic and transparent, it can be translated and used in other fields.

Several challenges were encountered in this FRN project, highlighting the importance of engaging a diverse stakeholder panel in the process. Since the evidence mapping covers a large number of topics, it was challenging to organize the large number of outcomes. The evidencemapping research team alone did not have sufficient 
Table 5 Considerations for future studies related to the top three high priority research questions

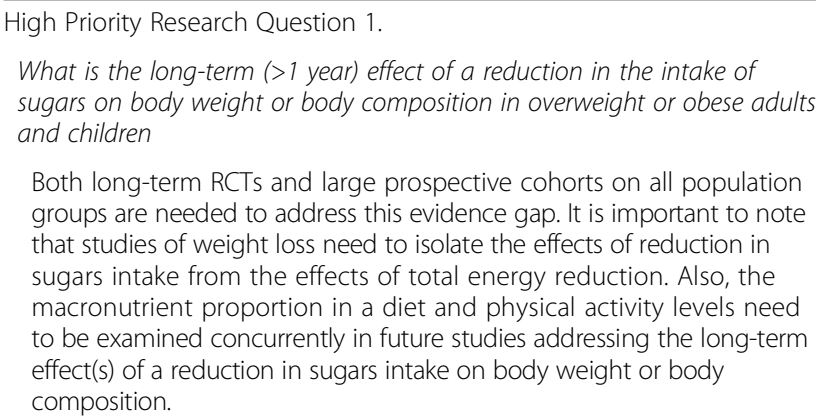

What is the long-term ( $>1$ year) effect of a reduction in the intake of sugars on body weight or body composition in overweight or obese adults and children

Both long-term RCTs and large prospective cohorts on all population groups are needed to address this evidence gap. It is important to note that studies of weight loss need to isolate the effects of reduction in sugars intake from the effects of total energy reduction. Also, the macronutrient proportion in a diet and physical activity levels need to be examined concurrently in future studies addressing the long-term effect(s) of a reduction in sugars intake on body weight or body composition.

High Priority Research Question 2.

Do dietary sugars have a different impact on body fat deposition than other macronutrients?

Both controlled human metabolic studies and basic science studies are needed to investigate this research question. The overall energy balance of the study design is important because iso- and hypercaloric intake may have different metabolic effects. The metabolic difference between iso- and hyper-caloric conditions is also in need of investigation. Moreover, the energy balance of any comparison group is an important design consideration in RCTs focused on teasing out effects of different types or sources of sugars on body composition while holding total energy constant. Overall study design is important in examining whether sugars or other macronutrients cause different patterns of fat deposition.

High Priority Research Question 3.

What is the effect of sugars intake on satiety and hunger mechanisms? Does sugars intake affect leptin and ghrelin levels, appetite, or fullness?

What are the different effects on satiety and appetite between different types of sugars (fructose, sucrose, high fructose corn syrup, honey, added sugar vs. intrinsic)?

A systematic evidence review of all published human studies on this topic is needed. Based on the evidence-mapping data, existing studies have generated highly variable outcomes, depending on the methodology used. An expert panel specifically on satiety and hunger mechanisms is needed to assist in the interpretations of the evidence base in order to identify existing methodological issues and to inform future research designs. Controlled, experimental studies to develop better measurement tools or to define reference biomarkers for measuring satiety, hunger and appetite are of higher priority than large scale population-based studies.

expertise to categorize the large number of biological markers and endpoints. This challenge was resolved by seeking stakeholders' input. However, our stakeholders also had different opinions in grouping and analyzing outcomes because of their diverse backgrounds and expertise. Final decisions were made based on a majority of the stakeholders' opinions. Therefore it is likely that a different panel of stakeholders could reach different decisions. Moreover, it was difficult to define the ideal composition of a stakeholder panel when the topic areas of FRN discussions are broad. Efforts were made to create a diverse stakeholder panel across seven areas of expertise but it is inevitable that our panel did not represent all perspectives. Due to budgetary constraints, we did not use the Delphi method [31] to facilitate the consensus process of the
Table 6 Cross-cutting study design considerations Crosscutting Issues Identified by the Stakeholder Panel

- Future research should use experimental conditions that approximate realistic intake levels and chemical forms.

- There is a need to improve dietary assessment tools and methodology because of ongoing concerns regarding systematic biases and random errors in dietary surveys or dietary assessment methods. The inadequacy of current methods that can potentially invalidate the scientific findings has been discussed elsewhere [33-36].

- Controlled feeding studies cannot answer population questions.

- Statisticians or researchers with adequate statistical expertise should be involved in a study to ensure that appropriate statistical methods are used to control for confounders and to adjust for random measurement errors in dietary intake assessments.

- The effect of fructose intake on blood lipids has been well established $[8,37-39]$; therefore there is no research need for this question. This is more of a biological mechanism question than a public health question.

- Diet quality could be an intermediate outcome for short- or long-term (more than 1 year) clinical outcomes.

- Diet quality and meal patterns may modify the response to dietary sugars and may need to be considered as a parameter for all studies.

- There are currently no biomarkers for sugars intake and appetite that are considered "gold standards."

- Body composition can change independent of weight and should be measured whenever possible.

- Current tools to measure adiposity are either invasive or very costly.

- Exercise, fitness, and levels of other forms of physical activity will likely modify many responses to dietary sugars and should be considered in all studies.

- Physical activity must be measured objectively (e.g., accelerometry based activity monitors) in clinical trials and observational studies.

- All domains of physical activity (e.g., occupational, household, transport, leisure-time, exercise, etc.) must be measured on the population level. The measurement of one or two domains (e.g., leisure-time and exercise) is inadequate.

- Individual genetics may modulate effects of sugars, resulting in heterogeneity of results

- There might be epigenetic and microbiome modulation of effects.

- There is a potential for the effects of sugars on the gut microbiome to mediate biological effects of sugars.

- There is evidence for the hypothesis that circadian timing of intake modulates biological effect.

stakeholder panel nor formally evaluate this FRN process. Significantly more resources (time and money) are needed to accomplish this goal. Our evidence mapping implemented a single screening process for eligible studies, so it is possible that a few abstracts were mistakenly rejected during this screening phase. In an effort to ensure all key studies were included, all included citations were crossreferenced with the reference list of relevant systematic reviews and meta-analyses. Finally, including members of the lay public in the FRN discussions was important to ensure that research questions were meaningful to general consumers, but engaging a lay audience in the panel discussions was challenging. Some lay members may have 
felt intimidated or may have been unable to follow the FRN discussions due to lack of familiarity with scientific language. Additional training and orientation of the roles of a lay audience in FRN discussions may mitigate this challenge. Although our FRN approach seems promising, there is still a need to evaluate whether this process is reproducible with a different group of equivalently representative stakeholders, and to formally conduct process evaluations to identify areas for improvement.

\section{Conclusions}

Involving stakeholders of different backgrounds in the research process, and using a multidisciplinary stakeholder panel to help prioritize the direction of future research may have the potential to add diverse perspectives on how research needs are defined or determined, and to inform public health policy. Too often researchers are removed from the people affected by their research -general public/patients, practitioners/providers, or policy makers. Our experience is in line with the Patient-Centered Outcome Research Institute (PCORI), with a mission to bring together all healthcare stakeholders - focusing on the community of patients to help set research priorities to ensure that the most relevant research is funded and conducted. A methodological research study found that AHRQ's FRN projects demonstrated greater short-term (e.g., greater awareness of the issues) than medium-term outcomes (e.g., the generation of new knowledge) or long-term impact outcomes (e.g., changes in patient practice or health outcome) [32]. We expect our FRN project would have similar impacts. Moreover, our open evidence-map database can be used by researchers, research funders and policy makers to identify research gaps and to evaluate the quantity of evidence accumulated for a specific research questions. Hence it has the potential to promote dissemination and generation of new knowledge. With continuous updating and data quality control, our open evidence-map database would have the potential to promote knowledge translation from nutrition science to policy.

\section{Additional files}

Additional file 1: Report Front Matter \& Appendices. (PDF 4393 kb)

Additional file 2: Evidence Mapping Methods. (PDF $143 \mathrm{~kb}$ )

\section{Acknowledgements}

The authors thank Joanne Spahn for contributions as a member of stakeholder panel in this project, Courtney Gaine for coordinating the in-person stakeholder meeting, and Samantha Berger, Joachim Sackey, Carrie Brown, and Grace Chan for their contributions to data collection and analysis of the evidence-map database.

\section{Funding}

The project is supported by the Technical Committee on Carbohydrates of the International Life Sciences Institute (ILSI) North American Branch. ILSI North America is a public, nonprofit foundation that provides a forum to advance understanding of scientific issues related to the nutritional quality and safety of the food supply by sponsoring research programs, educational seminars and workshops, and publications. ILSI North America receives financial support primarily from its industry membership. The sponsor had no role in FRN assessment or preparation of the final report and manuscript.

\section{Availability of data and materials}

All of the data are available within the manuscript and the additional files. The extracted data for all studies included in the evidence-map database can be accessed via Systematic Review Data Repository ${ }^{\mathrm{TM}}$ http://srdr.ahrq. gov/projects/136.

\section{Authors' contributions}

MC conceptualized, designed, and conducted the research. DW conducted the evidence-mapping analyses and coordinated the FRN project. AT provided editorial support and input on the considerations for future studies. EA, JH, SK $M L, L Q, S R, R D S, J S, D S$, and HW are the members of the stakeholder panel in this project, and they participated in research needs identification, discussions, and prioritization process. MC drafted the manuscript and the stakeholder pane commented and critically revised the manuscript. All authors contributed intellectually to this project and have read and approved the final manuscript

\section{Competing interests}

The following authors have no conflicts of interest to disclose: M Chung, DD Wang, J Higgins, S Kim, R Siegel, J Slavin, and AM Tang. E Archer have received unrestricted research funds from The Coca-Cola Company (not related to this FRN project) and declared no significant financial conflicts of interest. M Laughlin is an extramural program official of NIDDK $(\mathrm{NIH})$ and has grants in her portfolio dealing with fructose and sugar metabolism. L Qi is a consultant to Genovive, LLC. S Raatz received a grant from the National Honey Board (not relating to this FRN project). D Steffen has clients in the industry settings. H Warshaw is a consultant to Splenda Brand Sweetener and Ingredion, Inc.

Consent for publication

Not applicable.

Ethics approval and consent to participate

The activities performed in this study are not considered to be human subjects research, and therefore are exempt from IRB review.

\section{Author details}

${ }^{1}$ Nutrition/Infection Unit, Department of Public Health and Community Medicine, School of Medicine, Tufts University, Medford, USA. ${ }^{2} \mathrm{D} \& \mathrm{~V}$ Systematic Evidence Review Consulting, LLC, New York, USA. ${ }^{3}$ University of Alabama, Tuscaloosa, USA. ${ }^{4}$ University of Colorado Anschutz Medical Campus, Aurora, USA. ${ }^{5}$ Sery Kim, LLC, Washington D.C, USA. ${ }^{6}$ National Institute of Diabetes and Digestive and Kidney Diseases, National Institutes of Health, Bethesda, USA. ${ }^{7}$ Harvard T.H. Chan School of Public Health, Boston, USA. ${ }^{8}$ USDA, ARS, NPA, Grand Forks Human Nutrition Research Center, Grand Forks, USA. ${ }^{9}$ Division of Diabetes, Endocrinology and Metabolism, Tufts Medical Center, Boston, USA. ${ }^{10}$ Department of Food Science and Nutrition, University of Minnesota, Minneapolis, USA. ${ }^{11}$ A-D Policy Analysis Inc., Sarasota, USA. ${ }^{12}$ Hope Warshaw Associates, LLC, Washington D.C, USA.

Received: 21 June 2016 Accepted: 7 November 2016 Published online: 14 November 2016

\section{References}

1. Carey TS, Sanders GD, Viswanathan M, Trikalinos TA, Kato E, Chang S. Framework for considering study designs for future research needs [internet]. Rockville: Agency for Healthcare Research and Quality (US); 2012. Available from http://www.ncbi.nlm.nih.gov/books/NBK95273/.

2. Future Research Needs. Content last reviewed June 2014. Agency for Helathcare Quality and Research, Rockville, MD Available from http://www. ahrq.gov/research/findings/evidence-based-reports/technical/future/index. html. [Assessed 16 Oct 2016]. 
3. Future Research Needs - Methods Research Series. June 16, 2010. Agency for Helathcare Quality and Research, Rockville, MD Available from https:// www.effectivehealthcare.ahrq.gov/search-for-guides-reviews-and-reports/ ?pageaction=displayProduct\&productID=481. [Assessed 16 Oct 2016].

4. Cozma Al, Sievenpiper JL, de Souza RJ, Chiavaroli L, Ha V, Wang DD, Mirrahimi A, Yu ME, Carleton AJ, Di Buono M, Jenkins AL, Leiter LA, Wolever TM, Beyene J, Kendall CW, Jenkins DJ. Effect of fructose on glycemic control in diabetes: a systematic review and meta-analysis of controlled feeding trials. Diabetes Care. 2012;35:1611-20.

5. David Wang D, Sievenpiper JL, de Souza RJ, Cozma Al, Chiavaroli L, Ha V, Mirrahimi A, Carleton AJ, Di Buono M, Jenkins AL, Leiter LA, Wolever TM, Beyene J, Kendall CW, Jenkins DJ. Effect of fructose on postprandial triglycerides: a systematic review and meta-analysis of controlled feeding trials. Atherosclerosis. 2014;232:125-33.

6. Ha V, Sievenpiper JL, de Souza RJ, Chiavaroli L, Wang DD, Cozma Al, Mirrahimi A, Yu ME, Carleton AJ, Dibuono M, Jenkins AL, Leiter LA, Wolever M, Beyene J, Kendall CW, Jenkins DJ. Effect of fructose on blood pressure: a systematic review and meta-analysis of controlled feeding trials. Hypertension. 2012;59:787-95.

7. Sievenpiper JL, Carleton AJ, Chatha S, Jiang HY, de Souza RJ, Beyene J, Kendall CW, Jenkins DJ. Heterogeneous effects of fructose on blood lipids in individuals with type 2 diabetes: systematic review and meta-analysis of experimental trials in humans. Diabetes Care. 2009;32:1930-7.

8. Sievenpiper JL, Chiavaroli L, de Souza RJ, Mirrahimi A, Cozma Al, Ha V, Wang DD, Yu ME, Carleton AJ, Beyene J, Di Buono M, Jenkins AL, Leiter LA, Wolever TM, Kendall CW, Jenkins DJ. 'Catalytic' doses of fructose may benefit glycaemic control without harming cardiometabolic risk factors: a small meta-analysis of randomised controlled feeding trials. Br J Nutr. 2012;108:418-23.

9. Sievenpiper JL, de Souza RJ, Mirrahimi A, Yu ME, Carleton AJ, Beyene J, Chiavaroli L, Di Buono M, Jenkins AL, Leiter LA, Wolever TM, Kendall CW, Jenkins DJ. Effect of fructose on body weight in controlled feeding trials: a systematic review and meta-analysis. Ann Intern Med. 2012;156:291-304.

10. Te Morenga L, Mallard S, Mann J. Dietary sugars and body weight: systematic review and meta-analyses of randomised controlled trials and cohort studies. BMJ. 2013;346:e7492

11. Kaiser KA, Shikany JM, Keating KD, Allison DB. Will reducing sugar-sweetened beverage consumption reduce obesity? evidence supporting conjecture is strong, but evidence when testing effect is weak. Obes Rev. 2013;14:620-33.

12. Chung M, Ma J, Patel K, Berger S, Lau J, Lichtenstein AH. Fructose, high-fructose corn syrup, sucrose, and nonalcoholic fatty liver disease or indexes of liver health: a systematic review and meta-analysis. Am J Clin Nutr. 2014;100:833-49.

13. Wang DD, Shams-White M, Bright OJ, Parrott JS, Chung M. Creating a literature database of low-calorie sweeteners and health studies: evidence mapping. BMC Med Res Methodol. 2016;16:1.

14. Concannon TWMP, Grunbaum JA, McElwee N, Guise JM, Santa J, Conway $\mathrm{PH}$, Daudelin D, Morrato EH, Leslie LK. A new taxonomy for stakeholder engagement in patient-centered outcomes research. J Gen Intern Med. 2012;27:985-91.

15. Andrews J. Prioritization criteria methodology for future research needs proposals within the effective health care program: PiCMe-prioritization criteria methods [internet]. Rockville: Agency for Healthcare Research and Quality (US); 2013. Available from http://www.ncbi.n/m.nih.gov/books/NBK116679/.

16. Borgen I, Aamodt G, Harsem N, Haugen M, Meltzer HM, Brantsaeter AL. Maternal sugar consumption and risk of preeclampsia in nulliparous Norwegian women. Eur J Clin Nutr. 2012;66(8):920-5.

17. Burger KN, Beulens JW, van der Schouw YT, Sluijs I, Spijkerman AM, Sluik D, et al. Dietary fiber, carbohydrate quality and quantity, and mortality risk of individuals with diabetes mellitus. PLoS One. 2012;7(8):e43127.

18. Forman JP, Choi H, Curhan GC. Fructose and vitamin C intake do not influence risk for developing hypertension. J Am Soc Nephrol. 2009;20(4):863-71.

19. Garcia-Palmieri MR, Sorlie P, Tillotson J, Costas Jr R, Cordero E, Rodriguez M. Relationship of dietary intake to subsequent coronary heart disease incidence: the Puerto Rico heart health program. Am J Clin Nutr. 1980;33(8):1818-27.

20. Halkjaer J, Tjonneland A, Thomsen BL, Overvad K, Sorensen TI. Intake of macronutrients as predictors of 5-y changes in waist circumference. Am J Clin Nutr. 2006;84(4):789-97.

21. Hodge AM, English DR, O'Dea K, Giles GG. Glycemic index and dietary fiber and the risk of type 2 diabetes. Diabetes Care. 2004;27(11):2701-6.

22. Janket SJ, Manson JE, Sesso H, Buring JE, Liu S. A prospective study of sugar intake and risk of type 2 diabetes in women. Diabetes Care. 2003;26(4):1008-15.
23. Marshall JA, Bessesen DH, Hamman RF. High saturated fat and low starch and fibre are associated with hyperinsulinaemia in a non-diabetic population: the San Luis valley diabetes study. Diabetologia. 1997:40(4):430-8.

24. Suadicani $P$, Hein HO, Gyntelberg F. Adverse effects on risk of ischaemic heart disease of adding sugar to hot beverages in hypertensives using diuretics. A six year follow-up in the Copenhagen male study. Blood Press. 1996:5(2):91-7.

25. Taylor EN, Curhan GC. Fructose consumption and the risk of kidney stones. Kidney Int. 2008;73(2):207-12.

26. Tsai CJ, Leitzmann MF, Willett WC, Giovannucci EL. Dietary carbohydrates and glycaemic load and the incidence of symptomatic gall stone disease in men. Gut. 2005;54(6):823-8.

27. Guideline: Sugars intake for adults and children. Geneva: World Health Organization; 2015. Available from http://www.who.int/nutrition/ publications/guidelines/sugars_intake/en/ [Accessed 20 Oct 2016]

28. Domingos Al, Sordillo A, Dietrich MO, Liu ZW, Tellez LA, Vaynshteyn J, Ferreira JG, Ekstrand MI, Horvath TL, de Araujo IE, Friedman JM. Hypothalamic melanin concentrating hormone neurons communicate the nutrient value of sugar. Elife. 2013;2:e01462.

29. Li AJ, Wang Q, Dinh TT, Powers BR, Ritter S. Stimulation of feeding by three different glucose-sensing mechanisms requires hindbrain catecholamine neurons. Am J Physiol Regul Integr Comp Physiol. 2014;306:R257-64.

30. DiMeglio DP, Mattes RD. Liquid versus solid carbohydrate: effects on food intake and body weight. Int J Obes Relat Metab Disord. 2000;24:794-800.

31. Boulkedid R, Abdoul $H$, Loustau M, Sibony O, Alberti C. Using and reporting the Delphi method for selecting healthcare quality indicators: a systematic review. PLoS One. 2011;6(6):e20476.

32. Viswanathan M, Nerz P, Dalberth B, Voisin C, Lohr KN. Assessing the impact of AHRQ evidence-based practice center (EPC) reports on future research [internet]. Rockville: Agency for Healthcare Research and Quality (US); 2011. Available from http://www.ncbi.nlm.nih.gov/books/NBK62159/.

33. Schoeller DA, Thomas D, Archer E, Heymsfield SB, Blair SN, Goran Ml, Hill JO, Atkinson RL, Corkey BE, Foreyt J, et al. Self-report-based estimates of energy intake offer an inadequate basis for scientific conclusions. Am J Clin Nutr. 2013;97:1413-5.

34. Archer E, Hand GA, Blair SN. Validity of U.S. Nutritional surveillance:National health and nutrition examination survey caloric energy intake data, 1971-2010. PLoS One. 2013;8:e76632

35. Ioannidis JP. Implausible results in human nutrition research. BMJ. 2013;347:66698

36. Archer EPG, Lavie CJ. The inadmissibility of what we eat in America and NHANES dietary data in nutrition and obesity research and the scientific formulation of National dietary guidelines. Mayo Clin Proc. 2015;90:911-26. 37.

37. Zhang $Y H, A n T$, Zhang RC, Zhou Q, Huang Y, Zhang J. Very high fructose intake increases serum LDL-cholesterol and total cholesterol: a meta-analysis of controlled feeding trials. J Nutr. 2013;143(9):1391-8.

38. Sonestedt E, Overby NC, Laaksonen DE, Birgisdottir BE. Does high sugar consumption exacerbate cardiometabolic risk factors and increase the risk of type 2 diabetes and cardiovascular disease? Food Nutr Res. 2012;56. doi: 10.3402/fnr.v56i0.19104. PubMed PMID: 22855643; PubMed Central PMCID: PMC3409338.

39. Livesey G, Taylor R. Fructose consumption and consequences for glycation, plasma triacylglycerol, and body weight: meta-analyses and meta-regression models of intervention studies. Am J Clin Nutr. 2008;88(5):1419-37.

\section{Submit your next manuscript to BioMed Central and we will help you at every step:}

- We accept pre-submission inquiries

- Our selector tool helps you to find the most relevant journal

- We provide round the clock customer support

- Convenient online submission

- Thorough peer review

- Inclusion in PubMed and all major indexing services

- Maximum visibility for your research

Submit your manuscript at www.biomedcentral.com/submit 